\title{
Progress towards sustainable development goals at provincial level in Vietnam
}

\author{
Thi Mai Lan Nguyen ${ }^{1, *}$, Thuy Hao $\mathrm{Ngo}^{2}$, and Minh Nguyet $\mathrm{Le}^{3}$ \\ ${ }^{1}$ Graduate Academy of Social Sciences, 477 Nguyen Trai street, Thanh Xuan district, Hanoi, 10000, \\ Vietnam \\ ${ }^{2}$ Xiamen University, No. 442, Siming South Road, Xiamen, Fujian, 363105, China. \\ ${ }^{3}$ Ha Noi National University of Education, 136 Xuan Thuy street, Cau Giay district, Hanoi, 10000, \\ Vietnam
}

\begin{abstract}
This study focuses on assessing the progress towards SDGs in terms of the People aspect in Viet Nam by provincial level over the years. We quantify the implementation of the sustainable goals with respect to the People pillar in 25 provinces in Northern Vietnam over the last decade. The research results show that, in general, there has been much progress in the last many years. However, the performances are uneven across provinces. There is a large gap between the provinces in the Northern key industrial economic zone (NKEZ) and the mountainous areas. The results of this research can contribute to the development of a monitoring program, providing the information needed for policymakers to make decisions and develop policies that are appropriate and effective to achieve those sustainable development goals for industrial development in Vietnam.
\end{abstract}

\section{Introduction}

Sustainable development has become the common strategy for the whole world. Sustainable development is development that meets the needs of the present without compromising the ability of future generations to meet. their own need. The overall goal of sustainable development is the long-term stability of economics, environment and society which can only be achieved through the integration and recognition of economic, environmental and social concerns throughout decision making process.

On December 24, 2009, the United Nations held a conference on Sustainable Development (UNCSD) in Rio De Janeiro. At this Congress, the Rio Declaration was agreed upon, which outlined 27 principles for the achievement of sustainable development globally. All of these principles are built on the overarching concept of sustainable development established by the Brundtland Commission in 1987. From here, Agenda 21 on sustainable development and the Millennium Development Goals has become a global development strategy.

Assessing and determining the level of sustainable development is often conducted to support decision making and policy development in a broad context, becoming a common

\footnotetext{
* Corresponding author: mailantamly@gmail.com
} 
practice in many aspects such as products, policies and institutional appraisals (Serenella Sala; Biagio Ciuffo; Peter Nijkamp, 2015). Sustainability assessment is a method that can help policymakers decide what actions they should take for the sustainable development of the society (Devuyst, D., 2001). Sustainability assessment is any process that: contributes to a better understanding of the meaning of sustainability and its contextual interpretation (interpretation challenge); integrate sustainability issues into decision making by identifying and assessing sustainable impacts (past and/ or future) (information-structuring challenge); promoting sustainability goals (influence challenge) (Tom Waas, 2014). The goal of sustainability assessments is to pursue plans and trigger optimal contributions to sustainable development (Verheem, R., 2002). Sustainability assessments (SA) and sustainability indicators (SI) are important tools in addressing three above challenges: interpretation, information-structuring and influence challenges. However, the holistic and multidimensional nature of sustainable development with its uncertainties and risks make its assessment and measurement complex (Suvi Lehtoranta et al., 2011). Assessing the process of implementing sustainable development goals at the global, national and local levels is extremely important because it will help describe the level of achieving the goal and provide insight into the challenges of decision making, planning the implementation of sustainable development goals in the future.

In the process of realizing sustainable development goals in each nation, industry plays a central role. Industry is the most important sector in the entire national economy. There will be no sustainable development society without industrial sustainable development (Haidong Li, Shanyong Wang, Dingtao Zhao, 2012). Some scholars began to study industrial sustainability such as Hilson Gavin and Busu Arun J. (2003). Industrialization is important for economic growth and employment in all countries. There is ample evidence to show that industry and manufacturing provide greater opportunities to exploit large-scale economies, promote investment and innovation, create formal employment, and facilitate global trade. This recognition is based on the possibility of structural transformation of economies, which is the key to realizing economic growth and employment opportunities to achieve the goal of sustainable prosperity. However, industrialization can also be considered the main culprit for resource consumption and environmental hazard (UNEP, 2002). The industrial sector, has contributed to serious environmental pollution and exploitation of the ecological environment. Industry is also rapidly developing in many Asian countries and increasing soil, water and air pollution, raising concerns about the unsustainability of current economic development models (Tseng et al. (2013). Therefore, for the sake of industrial sustainable development, it is necessary to take into account both the advantages and consequences of industrialization in the achievement of the sustainable development goals.

Sustainable industrial development emphasizes the implementation of a number of measures by government, business, international cooperation, culture and education, financial capital and other fields to ensure enhancing sustainable industrial development (Haidong Li, Shanyong Wang, Dingtao Zhao, 2012; Jiao, W., \& Boons, F., 2014). The characteristics of sustainable development are pushing industrialization to a new path, featuring high-tech manufacturing, cleaner production, low resource consumption, less environmental pollution, and advantages in human resources (Bonilla et al., 2010). The United Nations argues that industrial systems can represent economic integration (Suvi Lehtoranta et al., 2011). Industrialization can be considered as a catalyst contributing to ecological development, social transformation and modernization (UNEP, 2002).

People are the wealth of each nation. Development should first and essentially revolve around people (UNDP, 1990). Therefore, people are one of the important factors of sustainable development. People along with the planet, prosperity, peace and cooperation are 5 pillars of sustainable development. The measurement of progress or the goal of sustainable development focuses on these 5 pillars (Sustainability Knowledge Group, 2018). Therefore, 
in terms of sustainable development in general and industrial sustainable development in particular, the human aspect plays a very important role. The evaluation and measurement of the progress towards industrial sustainable development goals in each period cannot be separated from the assessment of human aspects, including SDG1 - no poverty; SDG2 - zero hunger; SDG3 - good health and well-being; SDG4 - quality education; SDG5 - gender equality ((Sustainability Knowledge Group, 2018).

Vietnam, as a member state of the United Nations, has been actively involved in the implementation of the 2030 Agenda for Sustainable Development (GSO). The concept of sustainable development in Vietnam is integrated throughout socio-economic development strategies and plans and is concretized in the National Action Plan for implementation of the 2030 Agenda. The set of sustainable development indicators of Vietnam was issued in accordance with the Circular No. 03/2019 / TT-BKHDT dated January 22, 2019 of the Minister of Planning and Investment, including 158 targets. In particular, 38 indicators belong to the national statistical indicator system issued together with the Law on Statistics in 2015; 103 indicators are developed in accordance with the global sustainable development targets, 18 remaining indicators will have a roadmap and be collected and synthesized by 2025. The goal of sustainable development is a universal action plan for people, the planet, prosperity, peace and partnership (UNICEF, 2018). According to the national plan, sustainable development is defined as the task of all levels, sectors and the whole society, putting people at the center of the development process. People are at the center of sustainable development (VBCSD).

For Vietnam, industry is an important economic sector, making the largest contribution to the state budget, playing an important role in socio-economic development and affecting all three pillars of development. sustainable development (MPI, 2005). Therefore, Vietnam has adopted the Industrial Development Strategy to 2025, with a vision to 2035 (Prime Minister of Vietnam, 2014). The Politburo's Resolution on the orientation to formulate national industrial development policies by 2030 , with a vision to 2040 , also states that by 2030 Vietnam will achieve its goal of industrialization, modernization and mechanization, making Vietnam become one of the top three leading countries in ASEAN in terms of industry (Party Central Committee, 2018).

To promote the development of the country as well as to create collaboration and coordination in socio-economic development among economic regions, The Government of Vietnam has been trying to select a number of provinces/ cities. to form a national key economic region, creating a driving force for socio-economic development of the whole country at a high and sustainable speed, creating conditions for raising the living standards of the entire population. and quickly achieve social justice throughout the country. In that direction, at the end of 1997 and early 1998, the Prime Minister approved decision No. 747/1997 / QD-TTg, 1018/1997 / QD-TTg and Decision No. 44/1998 / QD- TTg on overall socio-economic development planning of three national key economic regions, including Northern key economic zone, Central key economic zone and Southern key economic zone. Therefore, this study focuses on assessing the progress of the implementation of the sustainable development goals in terms of People aspect by provincial level. Specifically, we evaluate sustainable development in the northern key industrial area in Vietnam by quantifying the sustainable goals in terms of the human aspect in 25 provinces in the Northern Vietnam over the last decade. The results of this research contribute to the development of a monitoring program, providing the information needed for policymakers to make decisions and develop policies that are appropriate, effective, and effective for a sustainable industrial development in Vietnam. 


\section{Materials and methods}

\subsection{Selecting indicators and collecting data}

Human Development Report, UN 2015c has mapped the SDGs into 5 areas, which are Planet, People, Prosperity, Peace and Partnership. The People element includes 5 SDGs, namely SDG1, SDG2, SDG3, SDG4, and SDG5. In this paper, we choose the indicators of those 5 SDGs, based on the national list of indicators for sustainable development in Vietnam (2018) Time seríes data are gathered from Statistical Yearbook of Vietnam, and some data for each province are collected individually on official province websites. There are big gaps for data availability at provincial level as well as over time. Only 1 third of the indicators have available data. The data for SDG5 is not available. Therefore, in this paper, we consider 4 SDGs in the People aspect. This research paper can be considered as a preliminary assessment for SDGs at provincial level, and future study could be work on more thorough assessment when more data are available.

\subsection{Normalization and aggregation}

To quantify the progress towards the SDGs, we use the method as in the UN report and dashboard 2018, and Xu et al. 2019. Each indicator is normalized into a range from a minimum of 0 to a maximum of 100 . Each province's progress will be scored according to that range, as follow:

$$
P_{i j}=\frac{x_{i j}-\min _{j}}{\max _{j}-\min _{j},}
$$

where:

$x_{i j}$ is the data of the province $\mathrm{i}$ with indicator $\mathrm{j}$.

$\min _{j}$ is the minimum value for indicator $\mathrm{j}$.

$\max _{j}$ is the maximum value for indicator $\mathrm{j}$

Then the performance index of SDGs for each province at goal level is calculated by simple mean, with all indicators are weighted equally, as follows :

$$
S_{i}=\sum_{j=1}^{N} \frac{1}{N} P_{i j},
$$

where $\mathrm{N}$ is the number of indicators for a specific goal.

A similar arithmetic mean will be conducted to measure the aggregated index score for 4 SDGs, where all 4 goals are weighted equally.

\subsection{Assessing the index scores}

There are 25 provinces in the Northern Vietnam. We will quantify the performance index of each province in the year of 2010, 2014 and 2018. In total, for each year investigated, we have 100 index scores at goal level for 25 provinces, plus 4 national index scores. Besides, 26 aggregated index scores are also collected for the overall performance of 4 SDGs each year. From those index scores, we can see the time-series changes of each province towards 
those SDGs, as well as the position of each province in Vietnam and among other provinces.

\section{Results}

The results shows that there has been much progress towards those SDGs in the Northern region of Vietnam. However, those progress are uneven among provinces. In 2010, only Hanoi had the performance score of more than 80, i.e 82.6. In the next 4 years, Bac Ninh, Quang Ninh and Hai Phong also achieved that level. 7 provinces of the North Key Economic Zone have been leading the way (Figure 1) while the mountainous provinces are still lagging behind, especially Lai Chau, Ha Giang, Dien Bien and Lao Cai.

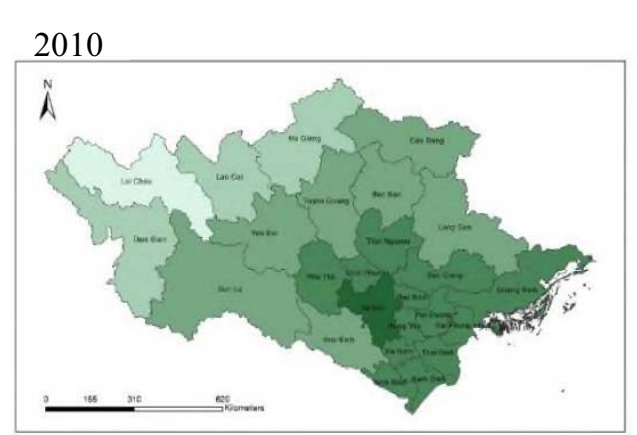

\section{4}
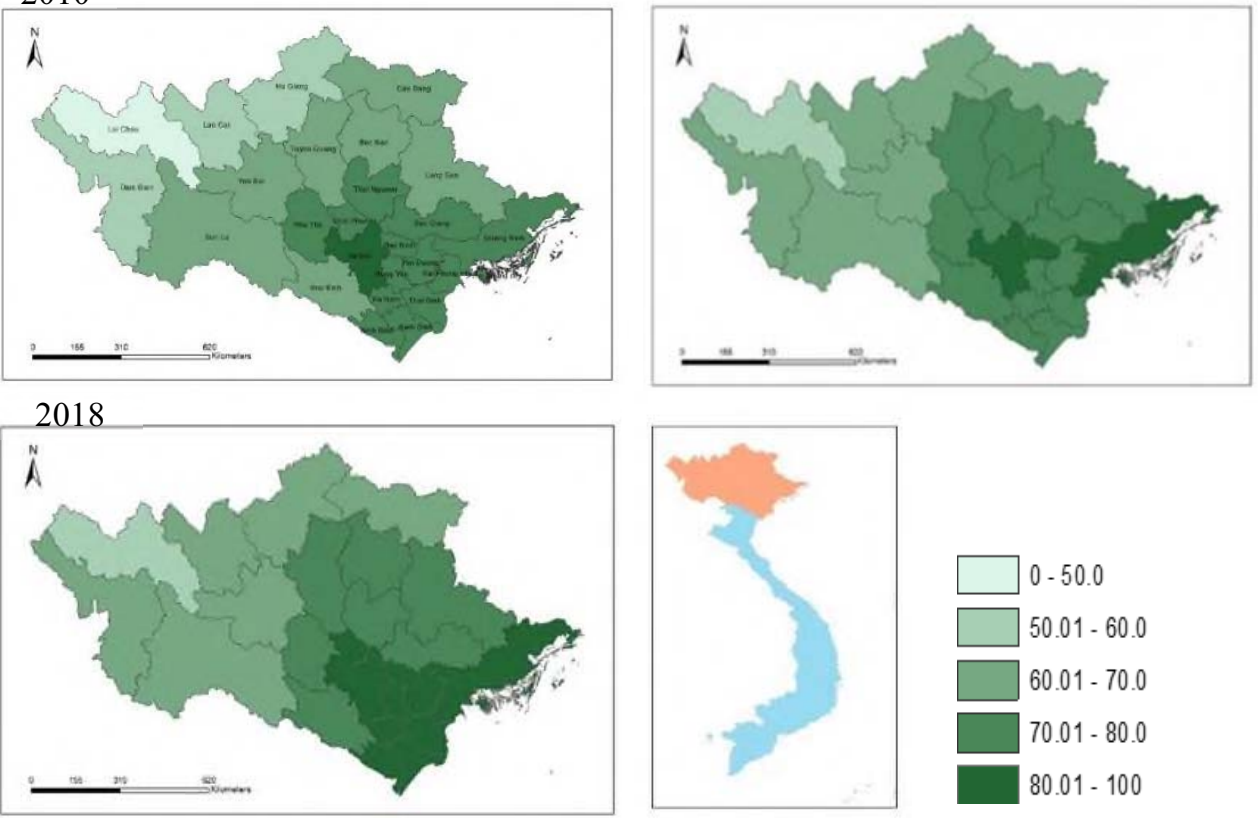

Fig. 1. The Performance scores of 25 provinces in Northern Vietnam in 2010, 2014 \&2018.

At national level, there has seen a great progress for SDG1 - erasing poverty. However, concerning the SDG4 - Quality Education, Vietnam still need much great effort, especially on the indicator of proportion of skilled and trained labors. The figures for this are small in every province, even in the NKEZ, where quality labors are of great important. Those figures range from about $20-40 \%$ of the labors who received proper training in the NKEZ. In mountainous areas, only $10-25 \%$ of the employees received proper training and education 


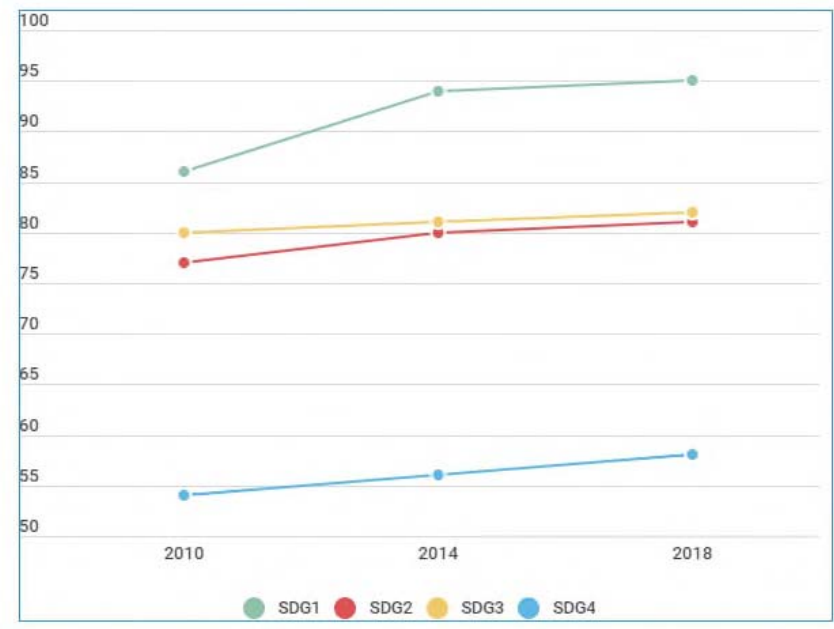

Fig. 2. The performance score for $4 \mathrm{SDG}$ of the People element of Vietnam over the years.

Our result also shows that there are 2 indicators that are most badly performed, which are the proportion of employees that receive proper training and education, and the mortality rate of children below 5 years old. Those are especially alarming in mountainous areas. In 2018 , the provinces that had the proportion of trained employees less than $20 \%$ included Hai Duong (17.6\%), Thai Binh (18.1\%), Nam Dinh (15.7\%), Ha Giang (13.4\%), Bac Kan (16.8\%), Tuyen Quang (19.2\%), Lao Cai (16.5\%), Lang Son (19.6\%), Bac Giang (16.6\%), Dien Bien (15.4\%), Lai Chau (14.9\%), Son La (14.6\%), Hoa Binh (16.8\%). Also in the same year, the mortality rate of children below 5 was markedly high in Ha Giang (49.7\%), Yen Bai (39.4\%), Lao Cai (42.2\%), Dien Bien (50\%) and Lai Chau (63.1\%). The other indicators of literate people, undernourishment, assessing to basic services such as health care and electricity,... are generally progressing a lot in the last decade in all provinces.
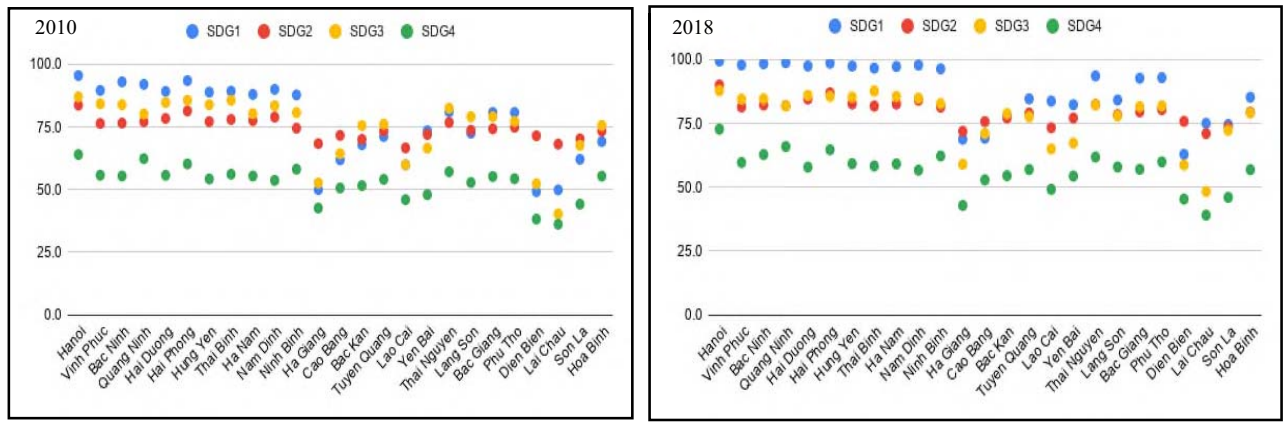

Fig. 2. Dashboard performance score for 4 goals of 25 provinces in 2010 and 2018.

\section{Discussion and conclusion}

Assessing the performance of SDGs in 25 provinces provides an overview on what benefits that industrial development has brought about for the people's well-being. All the indicators in terms of People aspect are higher in the industrial zone than the mountainous area. The variation in the performance scores across provinces may result from 2 reasons. First of all, the topographic characteristics and transportation network hinder the development of the mountainous areas. Coastal and Hong river delta provinces are centered for trading and 
transportation, which offers a more energetic and favorable place for living. Second, it is industrial development in the NKEZ (including Hanoi, Hai Phong, Quang Ninh, Hai Duong, Bac Ninh, Hung Yen, Vinh Phuc) that affects the scores. More job opportunities are created. The number of people living under the poverty line declines dramatically. More services for entertainment, education, healthcare etc are provided. Schools are better equipped. Teachers and professionals find those provinces in NKEZ more suitable for their career development. The education level of students and youngsters is therefore much higher, especially in terms of computer and language skills.

Besides, there is a variation among indicator scores within the industrial zone. For example, the proportion of employee with proper training is much lower than other indicators, such as proportion of undernourishment. Figuring out this result can help contribute to some programs or policies to enhance this score, which then can benefit the quality of labor and productivity for a sustainable industrial development.

Our study aims to measure the progress towards 5 SDGs in "People" aspect at provincial level because previous study often focus on national or subnational level, i.e regional level. However, we see that even in one region, the performance of provinces are different. For example, in the Northeast region, Thai Nguyen, Phu Tho and Quang Ninh perform much better than the other provinces in the same region. Moreover, municipal council will be in charge of its own province's development, so it is necessary to monitor the progress by provincial level so that each province know its position compared to other provinces and compared to the whole country

However, data gaps make this monitoring and assessment more difficult. About one quarter of data are available at provincial level. It also means that the robustness level is not high. We intended to measure 5 SDGs in the People aspect, but indicators of SDG5 at provincial level - gender equality are not recorded. So, instead, we tried to measure 4 SDGs to provide a preliminary overview of the performance of SDGs in our country, as well as to suggest improving the database system by provincial level for a more thorough assessment. This research results suggest more policies to erase the gaps among provinces and for "no one is left behind" - the ultimate goal of sustainable development. Municipal policy makers should look more closely to each of the indicators and set the priority for some indicators over others. People are at the center of sustainable development in Vietnam (Prime Minister of Vietnam, 2014). Enhancing indicators for People aspect are hence very important to ensure a sustainable industrial development. With a highly skilled labor workforce and quick technology development, the industrial development will boost quickly. And lifelong learning and creative education is key to achieve that high quality of labor workforce and high technology. Along with the industrial development, services of living are enhanced as well, including food security, healthcare system, education services and technology, entertainment services, etc. The results of this research can also contribute to the development of a monitoring program, providing the information needed for policymakers to make decisions and develop policies that are appropriate and effective to achieve those sustainable development goals for industrial development in Vietnam.

Future research should focus on assessing the trends towards SDGs, i.e. estimating if the countries or regions can reach the goals within the given time frame, so that proper policies could be proposed to accelerate the speed towards the SDGs. Besides, database system should be enhanced to help scientists and managers assess and monitor the progress more thoroughly and with a higher level of robustness.

\section{References}

1. S. H. Bonilla, Almeida, C. M. V. B. Almeida, B. F. Giannetti, \& D. Huisingh., Journal of Cleaner Production 18(1), 1-5 (2010) doi:10.1016/j.jclepro.2009.09.001 
2. P. Cerin, Bringing economic opportunity into line with environmental influence: A Discussion on the Coase theorem and the Porter and van der Linde hypothesis, 209-225 (Journal of Cleaner Production, 2006)

3. J. C. Dernbach, Sustainable development as a framework for national governance, 1-103 (Case Western Reserve Law Review, 1998)

4. J. C. Dernbach, Achieving sustainable development: The Centrality and multiple facets of integrated decisionmaking, 247-285 (Indiana Journal of Global Legal Studies, 2003)

5. D. Devuyst, How Green is the City? Sustainability Assessment and the Management of Urban Environments, 457S (Columbia University Press, New York, 2001)

6. General Statistics Office of Vietnam, Statistical Yearbook of Vietnam (2018)

7. GSO (General Statistics Office of Vietnam), Overview Of The Set Of Sustainable Development Statistical Indicators Of Vietnam

8. H. Gavin and A. J. Busu, International Journal for Sustainable Development \& World Ecology 4(4), 545-557 (2003)

9. H. D. Li, S. Y. Wang, D. T. Zhao, American Journal of Operations Research 2, 442-447 (2012) http://dx.doi.org/10.4236/ajor.2012.23052

10. W. Jiao, \& W. Boons, Journal of Cleaner Production 67, 14-25 (2014) doi:10.1016/j.jclepro.2013.12.050

11. MPI (Ministry of Planning and Investment) Formulation and Implementation of Viet Nam's Nationnal Agenda 21 (Vietnam, Hanoi) (2005)

12. Our Common Future, Report of the Brundtland Commission (1987). http://www. undocuments.net/wced-ocf.htm

13. Party Central Committee of Vietnam. Resolution of the Politburo on the orientation of formulating national industrial development policies by 2030, with a vision to 2040. (2018)

14. Prime Minister of Vietnam, Decision. Approving The Strategy On Vietnam's Industrial Development Through 2025, With A Vision Toward 2035 (2014)

15. J. Sachs, G. Schmidt-Traub, C. Kroll, G. Lafortune, and G. Fuller, SDG Index and Dashboards Report 2018 (New York: Bertelsmann Stiftung and Sustainable Development Solutions Network(SDSN), 2018)

16. S Sala, B Ciuffo, P Nijkamp, Ecological Economics 119, 314-325 (2015)

17. H. Stoddart, A Pocket guide to sustainable development governance (Stakeholder Forum, 2011)

18. Sustainability Knowledge Group, The Why's and How's of Sustainable Development Goals (SDGs) (2018). To get in touch and for more information contact us: Email: contact@sustainabilityknowledgegroup.com www.sustainabilityknowledgegroup.com

Website:

19. S. Lehtoranta, A. Nissinen, T. Mattila, M. Melanen, Journal of Cleaner Production 19(16), 1865-1875 (2011)

20. T. Waas, J. Hugé, T. Block, T. Wright, F. Benitez-Capistros, A. Verbruggen, Sustainability Assessment and Indicators: Tools in a Decision-Making Strategy for Sustainable Development. (Sustainability, 6, 1-x manuscripts, 2014) doi:10.3390/su60x000x

21. M. L. Tseng, A. S. F. Chiu, R. R. Tan, \& A. B. Siriban-Manalang, Journal of Cleaner Production 40, 1-5 (2013) doi:10.1016/j.jclepro.2012.07.015

22. UNDP. Human development report (1990) 
23. UNEP (United Nations Environment Programme). Industry and Sustainable Development. United Nations, Paris (2002)

24. UNICEF. Children and the Sustainable Development Goals (2018)

25. R. Verheem, Recommendations for sustainability assessment in the Netherlands. Incommission for EIA. Environmental impact assessment in the Netherlands (2002). ViewsFromtheCommissionforEIAin2002.TheNetherlands

26. VBCSD. Vietnam Business Council for Sustainable Development (2019)

27.Z. Xu, S. N. Chau, X. Chen, et al., Nature 577, 74-78 (2020) https://doi.org/10.1038/s41586-019-1846-3 